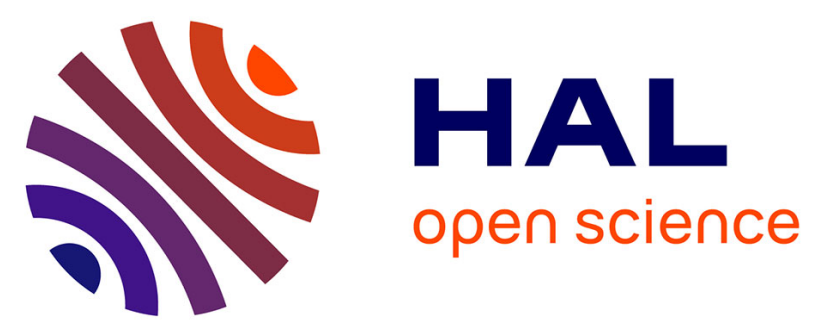

\title{
Inguinal Lymphadenectomy For Stage Iii Melanoma: A Comparative Study Of Two Surgical Approaches At The Onset Of Lymphoedema
}

Nicolas Bertheuil, Laurent Sulpice, Giovanni Battista Levi Sandri, Vincent Vincent.Lavoue@chu-Rennes.Fr Lavoué, Eric Watier, B. Meunier

\section{To cite this version:}

Nicolas Bertheuil, Laurent Sulpice, Giovanni Battista Levi Sandri, Vincent Vincent.Lavoue@chuRennes.Fr Lavoué, Eric Watier, et al.. Inguinal Lymphadenectomy For Stage Iii Melanoma: A Comparative Study Of Two Surgical Approaches At The Onset Of Lymphoedema. EJSO - European Journal of Surgical Oncology, 2014, in press. 10.1016/j.ejso.2014.10.062 . hal-01103387

\section{HAL Id: hal-01103387}

https://hal-univ-rennes1.archives-ouvertes.fr/hal-01103387

Submitted on 14 Jan 2015

HAL is a multi-disciplinary open access archive for the deposit and dissemination of scientific research documents, whether they are published or not. The documents may come from teaching and research institutions in France or abroad, or from public or private research centers.
L'archive ouverte pluridisciplinaire HAL, est destinée au dépôt et à la diffusion de documents scientifiques de niveau recherche, publiés ou non, émanant des établissements d'enseignement et de recherche français ou étrangers, des laboratoires publics ou privés. 
Editorial reference: YEJSO_EJSO-D-14-00463

To be published in: European Journal of Surgical Oncology

Title: Inguinal Lymphadenectomy For Stage Iii Melanoma: A Comparative Study Of Two Surgical Approaches At The Onset Of Lymphoedema

Introduction: When sentinel lymph node is positive for metastasis (exclusion for micro-metastasis) and in cases of palpable adenopathy, a lymphadenectomy should be performed. Many incisional surgical approach have been described in literature. We perform two type of incision (vertical with skin excision and transversal) for inguinal lymphadenectomy. The aim of this study was to compare post-operative morbidity between these two approach in cases of Stage III Melanoma. We analyzed chronic lymphoedeme, skin necrosis, wound dehiscence, wound infection and seroma rates between the two techniques.

Methods: From April 2000 to February 2012 fifty-three patients underwent to inguinal lymphadenectomy for Stage III melanoma at CHU of Rennes. Patients were stratified in 2 groups according to the surgical approach, group 1 with a vertical incision with skin excision and group 2 with a transverse incision.

Results: Chronic lymphedema rate for group 1 was $37.04 \%$ and for group 2 rate was $26.92 \%$, this complication was lower un group 2 but no significant difference was observed $(p=0.558)$. Skin necrosis $(p=0.235)$, wound dehiscence $(p=1.000)$, wound infection $(p=0.236)$ and seroma $(p=0.757)$ were not significantly different. Two cases of skin necrosis were observed in group $2(7.69 \%)$ and none in group 1.

Conclusion: We do not found significant difference for chronic lymphedema between these two approach. However, we had less lymphedema with the transversal technique which has the advantage to reduce the skin suffering when external iliac lymphadenectomy dissection is necessary in addition to the inguinal lymphadenectomy. 
INGUINAL LYMPHADENECTOMY FOR STAGE III MELANOMA: A COMPARATIVE STUDY OF TWO SURGICAL APPROACHES AT THE ONSET OF LYMPHOEDEMA

Nicolas Bertheuil ${ }^{1,4,5}$, Laurent Sulpice ${ }^{2}$, Giovanni Battista Levi Sandri², Vincent Lavoué ${ }^{3}$, Eric Watier $^{1}$, Bernard Meunier ${ }^{2}$.

1-Department of Plastic, Reconstructive, and Aesthetic Surgery, Hospital Sud, University of Rennes 1, 16 Boulevard de Bulgarie, 35200, Rennes, France

2-Service de Chirurgie Hépatobiliaire et Digestive, Hôpital Pontchaillou, Centre Hospitalier Universitaire, Université de Rennes 1, Rennes, France

3- Department of Gynecology, CHU Anne de Bretagne, Rennes, France

4- SITI Laboratory, Etablissement Français du Sang Bretagne, Rennes University Hospital, Rennes, France.

5- STROMAlab, UMR5273 CNRS/UPS/EFS - INSERM U1031, Rangueil Hospital, Toulouse, France.

Key Words: inguinal lymphadenectomy ; lymphedema ; stage III melanoma ; surgery

Words: 13966

Figure: 2

Table:2

References: 15 


\section{Introduction}

The incidence of melanoma has been increasing over the past few decades [1] and multidisciplinary treatment is recommended. A lymphadenectomy should be performed when sentinel lymph nodes are positive for metastasis (excluding micrometastases $<0.1 \mathrm{~mm}$ [2]) and in cases of palpable lymphadenopathy [3]. Many incisional surgical approaches have been described in the literature. To prevent the skin necrosis that is observed with vertical incisions, a modified technique has been described using an ellipse-shaped incision [4-6].

A transverse incision has been described when inguinal lymphadenectomy must be completed with external iliac lymphadenectomy. The transverse incision avoids a ' $\mathrm{T}$ ' incision and reduces skin lesions (wound dehiscence, skin necrosis). However, a few recent series have reported morbidity rates ranging from $10 \%$ to $50 \%$ with this technique $[4,7-8]$. The aim of this study was to compare post-operative morbidity between the transverse and vertical incision approaches in cases of stage III melanoma. We compared chronic lymphoedema, skin necrosis, wound dehiscence, wound infection and seroma rates between the two techniques.

\section{Materials and Methods}

From April 2000 to February 2012, 53 patients underwent inguinal lymphadenectomy for stage III melanoma at CHU Rennes. Patients were stratified into two groups according to the surgical approach that was used as follows: group 1 had vertical incisions and group 2 had transverse incisions. Clinical variables were compared between the two groups, including age, sex, height, weight, body mass index, smoking habits before surgery, histological type of melanoma, Breslow depth, Clark level, presence of ulceration and regression. Information regarding surgical complications, such as chronic lymphoedema, skin necrosis, wound dehiscence, wound infection, seroma and 1-year survival, was collected from all patients. Due to the retrospective nature of the study, lymphoedema was considered as 'present' or 'not present', and it was not possible to confirm the stage of lymphoedema in all patients. This study was approved by our Institutional Review Board, performed in accordance with 
the principles of the Declaration of Helsinki (1964) and was in agreement with French bioethics laws (7 July 2011). We obtained informed consent from all patients.

\section{Surgical Procedures}

The two procedures are described in Figure 1. In group 1 (Figure 1-A), a vertical incision with skin excision was made. Drawings were made with the patient in the supine position; an upper point was marked at the femoral pulse under the inguinal ligament and a lower point was marked at the junction between the adductor longus and the sartorius muscle. An ellipse was marked on the skin between these two points, the amount of skin resection is determined by pitching the skin. An incision was made on the superficial fascia, including the skin in the specimen. In group 2 (Figure 1-B), a transverse incision was made at a three-finger distance below the inguinal ligament. The decision regarding which incision to use was made by the surgeon in the operating room. The remaining steps of the surgical procedure were identical for both groups. Briefly, the great saphenous vein was systematically ligated, followed by lymphadenectomy of the tissue under the superficial fascial layer, over the aponeurosis of the adductor longus and over the aponeurosis of the sartorius up to the inguinal ligament deep to the femoral pedicle. Finally, two suction drains were placed and skin closure was achieved in three planes without tension using $2 / 0 \mathrm{Vicryl}[$ for the subcutaneous plane, $3 / 0$ Monocryl ${ }^{\circledR}$ for the intradermal plane and staples for the skin. A compression bandage was maintained until drain removal.

\section{Statistical Analysis}

Data analyses were performed using the SPSS statistical software (version 16.0 for Windows, SPSS, Inc., Chicago, IL, USA). The Student's t-test, Mann-Whitney U-test and Fisher test were used where appropriate. Statistical significance was defined by $\mathrm{p} \leq 0,5$.

\section{Results}


We retrospectively analysed 53 patients, 27 in group 1 (G1: vertical incision with skin excision) and 26 in group 2 (G2: transverse incision). The results are summarized in Table 1. No significant differences were observed in patient characteristics between the two groups. The mean age was 48.85 years (G1) vs. 56.73 years $(\mathrm{G} 2)(\mathrm{p}=0.071)$, the mean height was $167.58 \mathrm{~cm}(\mathrm{G} 1)$ vs. $169.35 \mathrm{~cm}(\mathrm{G} 2)$ $(\mathrm{p}=0.562)$ and the mean body mass index was $24.54 \mathrm{~kg} / \mathrm{m}^{2}(\mathrm{G} 1)$ vs. $25.24 \mathrm{~kg} / \mathrm{m}^{2}(\mathrm{G} 2)(\mathrm{p}=0.527)$. Similarly, no significant differences were found in $\operatorname{sex}(p=0.586)$, histological type $(p=0.293)$, Breslow depth $(\mathrm{G} 1=3.0 \mathrm{~mm}$ vs. $\mathrm{G} 2=3.1 \mathrm{~mm}, \mathrm{p}=0.516)$, Clark level $(\mathrm{p}=0.218)$, ulceration $(\mathrm{p}=$ $1.000)$ and regression $(\mathrm{p}=0.146)$.

No significant difference was observed in the rate of chronic lymphoedema between groups 1 $(37.04 \%)$ and $2(26.92 \%)(p=0.558)$. There were no significant differences in skin necrosis $(p=$ $0.235)$, wound dehiscence $(p=1.000)$, wound infection $(p=0.236)$ and seroma $(p=0.757)$ between the two groups. Furthermore, there was no significant difference in the 1-year survival $(p=1.000)$ between the two groups. The post-operative morbidity rates between the two groups are summarized in Table 2.

\section{Discussion}

Many previous studies have described modifications of the incisional techniques for inguinal lymphadenectomy because morbidity rates associated with this procedure remain high [4-7,9]. A prospective randomized study of two transverse incisions - one above, and one below, the inguinal ligament—was performed on 62 patients [10]. A higher complication rate was observed in the group whose incision was below the inguinal ligament (the same procedure described in our study) but no significant difference in chronic lymphoedema or survival was observed between the two groups.

In our study, the transverse incision was favoured because it avoided a $« \mathrm{~T} »$ incision in cases where crural or external iliac lymphadenectomy was required. Transverse incisions should reduce the risk of skin suffering. Although statistical significance was not achieved, less lymphoedema was observed in 
G2, which may be explained by the reduction in the 'tourniquet effect' observed in cases with a vertical incision, which is caused by healing in the member axis (Figure 2).

The vertical incision (as used in group 1) offers better exposure for lymphadenectomy but may increase skin suffering; thus, many surgeons perform an ellipse-shaped incision to reduce this risk (Figure 1-A).

We observed a higher complication rate of chronic lymphoedema in group 1 compared with group 2 (37.04\%vs.26.92\%, $\mathrm{p}=0.558)$, though the difference was not statistically significant. Two cases of skin necrosis were observed in group $2(7.69 \%)$ vs. none in group 1 . This may underline the utility of an ellipse-shaped incision to reduce skin suffering when a vertical incision is chosen.

No significant difference in lymphoedema was observed between the two groups. Previous authors have described procedures to decrease the incidence of lymphoedema, including preservation of the great saphenous vein $[8,11,12]$. Zhang et al. described a $50 \%$ decrease in lymphoedema with this method in a study of 64 patients with vulvar carcinoma, with no difference in survival was observed [12].

Dardarian et al. demonstrated a reduction in chronic lymphoedema from $39 \%$ to $11 \%(\mathrm{p}<0.05)$ associated with a reduction in cellulitis from $45 \%$ to $0 \%(\mathrm{p}<0.001)$ and a reduction in wound dehiscence from $25 \%$ to $0 \%(\mathrm{p}<0.02)$ [8]. A recent meta-analysis confirmed Dardarian's results regarding lymphoedema reduction with an odds ratio of 0.24 and a confidence interval of $0.11-0.53$ without local recurrence [11].

New solutions to reduce lymphoedema have been proposed. Preservation of muscular fascia was described with an associated incidence of chronic lymphoedema of 14\% [13], which is lower than both our series and other publications [7]. Sartorius transposition was evaluated and did not reduce postoperative wound morbidity [14]. Transplantation of the greater omentum in the treatment of chronic lymphoedema has been described with positive results, but it was a small case series and an abdominal approach was necessary $[11,15]$. 
Although our study was a retrospective cohort study, to the best of our knowledge, it is the first comparative study of these two incisional approaches for inguinal lymphadenectomy for stage III melanoma.

\section{Conclusions}

We did not find a significant difference in the incidence of chronic lymphoedema between patients who had transverse and vertical incisions. With regard to the complication rates of inguinal lymphadenectomy for stage III melanoma, we plan to conduct a prospective study comparing the two incisions to validate the present results.

Acknowledgment: Authors like to thank Camille Buscail, MD (service d'épidémiologie et de santé publique, Hopital Pontchaillou, CHU Rennes, Rennes, France) for statistic analysis.

Conflict of interest disclosure: All Authors do not have conflict of interest. This paper has not been funded.

\section{Figure Legends:}

Figure 1: The two-incision procedure. A: A vertical incision with an ellipse-shaped incision (Group 1) B: A transverse incision made at a three-finger distance below the inguinal ligament (Group 2).

Figure 2: A: A vertical incision. Blue arrows indicate the healing process; red arrows indicate the 'tourniquet effect'. B: A transverse incision. Blue arrows indicate the healing process that may avoid the 'tourniquet effect'. 
Reference :

1- Grange F. Epidemiology of cutaneous melanoma: descriptive data in France and Europe. Ann Dermatol Venereol. 2005 Dec;132(12 Pt 1):975-82.

2- van Akkooi AC, de Wilt JH, Verhoef C, et al. Clinical relevance of melanoma micrometastases $(<0.1 \mathrm{~mm})$ in sentinel nodes: are these nodes to be considered negative? Ann Oncol. 2006 Oct;17(10):1578-85. Epub 2006 Sep 12.

3- Négrier S, Saiag P, Guillot B et al. Clinical practice guideline: 2005 update of recommendations for the management of patients with cutaneous melanoma without distant metastases (summary report). Bull Cancer. 2006 Apr;93(4):371-84.

4- Baas PC, Schraffordt Koops H, Hoekstra HJ, van Bruggen JJ, van der Weele LT, Oldhoff J. Groin dissection in the treatment of lower-extremity melanoma. Short-term and long-term morbidity. Arch Surg. 1992 Mar;127(3):281-6.

5- Poos HP, Kruijff S, Bastiaannet E, van Ginkel RJ, Hoekstra HJ. Therapeutic groin dissection for melanoma: risk factors for short term morbidity. Eur J Surg Oncol. 2009 Aug;35(8):877-83. doi: 10.1016/j.ejso.2008.10.012. Epub 2008 Dec 2.

6- Van der Ploeg E, Schraffordt Koops H. A modified technique of groin dissection. Arch Chir Neerl. 1972;24(1):31-6.

7- van Akkooi AC, Bouwhuis MG, van Geel AN, et al. Morbidity and prognosis after therapeutic lymph node dissections for malignant melanoma. Eur J Surg Oncol. 2007 Feb;33(1):102-8. Epub 2006 Dec 11.

8- Dardarian TS, Gray HJ, Morgan MA, Rubin SC, Randall TC. Saphenous vein sparing during inguinal lymphadenectomy to reduce morbidity in patients with vulvar carcinoma. Gynecol Oncol. 2006 Apr;101(1):140-2. Epub 2005 Dec 20.

9- Fraley EE, Hutchens HC. Radical ilio-inguinal node dissection: the skin bridge technique. A new procedure. J Urol. 1972 Aug;108(2):279-81.

10-Manci N, Marchetti C, Esposito F, et al. Inguinofemoral lymphadenectomy: randomized trial comparing inguinal skin access above or below the inguinal ligament. Ann Surg Oncol. 2009 Mar;16(3):721-8. doi: 10.1245/s10434-008-0216-4.

11- Abbas S1, Seitz M. Systematic review and meta-analysis of the used surgical techniques to reduce leg lymphedema following radical inguinal nodes dissection. Surg Oncol. 2011 Jun;20(2):88-96. doi: 10.1016/j.suronc.2009.11.003. Epub 2009 Dec 11. 
12-Zhang X, Sheng X, Niu J, et al. Sparing of saphenous vein during inguinal lymphadenectomy for vulval malignancies. Gynecol Oncol. 2007 Jun;105(3):722-6. Epub 2007 Apr 3.

13- Lawton G, Rasque H, Ariyan S. Preservation of muscle fascia to decrease lymphedema after complete axillary and ilioinguinofemoral lymphadenectomy for melanoma. J Am Coll Surg. 2002 Sep;195(3):339-51.

14- Judson PL, Jonson AL, Paley PJ, et al. A prospective, randomized study analyzing sartorius transposition following inguinal-femoral lymphadenectomy. Gynecol Oncol. 2004 Oct;95(1):226-30.

15- Egorov YS, Abalmasov KG, Ivanov VV, et al. Autotransplantation of the greater omentum in the treatment of chronic lymphedema. Lymphology. 1994 Sep;27(3):137-43 
Table 2. Post operative morbidity rates between transverse and vertical incision

\begin{tabular}{|c|c|c|c|c|}
\hline Variable & & Group 1 & Group 2 & $\mathrm{p}$ value $(*)$ \\
\hline \multirow[t]{2}{*}{ Lymphedeme } & Yes & $10(37,04 \%)$ & $7 \quad(26,92 \%)$ & \multirow[b]{2}{*}{0,558} \\
\hline & no & $17(62,96 \%)$ & $19(73,08 \%)$ & \\
\hline \multirow[t]{2}{*}{ Skin necrosis } & Yes & $0 \quad(0,00 \%)$ & $2(7,69 \%)$ & \multirow{2}{*}{0,235} \\
\hline & no & $27(100,00 \%)$ & $24(92,31 \%)$ & \\
\hline \multirow[t]{2}{*}{ Wound dehiscence } & Yes & $4(14,81 \%)$ & $3(11,54 \%)$ & \multirow{2}{*}{1,000} \\
\hline & no & $23(85,19 \%)$ & $23(88,46 \%)$ & \\
\hline \multirow[t]{2}{*}{ Wound infection } & Yes & $3(11,11 \%)$ & $0(0,00 \%)$ & \multirow{2}{*}{0,236} \\
\hline & no & $24(88,89 \%)$ & $26(100,00 \%)$ & \\
\hline \multirow[t]{2}{*}{ Seroma } & Yes & $8(29,63 \%)$ & $6(23,07 \%)$ & \multirow{2}{*}{0,757} \\
\hline & no & $19(70,37 \%)$ & $20(76,93 \%)$ & \\
\hline \multirow[t]{3}{*}{ One year survival } & Yes & $20(88,96 \%)$ & $19(84,78 \%)$ & \multirow{3}{*}{1,000} \\
\hline & no & $3(13,04 \%)$ & $4(15,22 \%)$ & \\
\hline & Unknown & 4 & 3 & \\
\hline
\end{tabular}

* Fisher test 
Table 1. Patients characteristics

\begin{tabular}{|c|c|c|c|c|c|c|}
\hline \multicolumn{2}{|l|}{ Variable } & Group 1 & \multicolumn{2}{|r|}{ Group 2} & \multicolumn{2}{|c|}{$\begin{array}{c}\mathrm{p} \text { value } \\
(*, * *, * * *)\end{array}$} \\
\hline Number & & 27 & 26 & & & \\
\hline Age & & $48,85+/-15,89$ & 56,73 & $+/-15,29$ & 0,071 & $*$ \\
\hline Size & & $167,58+/-9,75$ & 169,35 & $+/-9,70$ & 0,562 & $*$ \\
\hline Weigh & & $63,37+/-13,19$ & 72,16 & $+/-12,36$ & 0,326 & $*$ \\
\hline \multirow[t]{2}{*}{ Gender } & Men & $11(40,74 \%)$ & 13 & $(50,00 \%)$ & \multirow{2}{*}{0,586} & \multirow{2}{*}{ *** } \\
\hline & Women & $16(59,26 \%)$ & 13 & $(50,00 \%)$ & & \\
\hline \multirow[t]{3}{*}{ Smoke } & non-smoker & $18(66,67 \%)$ & 11 & $(73,33 \%)$ & \multirow{3}{*}{0,739} & \multirow{3}{*}{ *** } \\
\hline & smoker & $9(33,33 \%)$ & 4 & $(26,67 \%)$ & & \\
\hline & unknown & . & 11 & & & \\
\hline \multicolumn{7}{|c|}{ Histological type of melanoma } \\
\hline & SSM & $17(73,91 \%)$ & & $(53,33 \%)$ & \multirow{6}{*}{0,293} & \multirow{6}{*}{$* * *$} \\
\hline & Nodular & $3(13,04 \%)$ & 4 & $(26,67 \%)$ & & \\
\hline & Acral & $1(4,35 \%)$ & 3 & $(20,00 \%)$ & & \\
\hline & Acromic & $1(4,35 \%)$ & & & & \\
\hline & Spitz & $1(4,35 \%)$ & & & & \\
\hline & unknown & 4 & 11 & & & \\
\hline Breslow & $(\mathrm{mm})$ & $3,00 \quad(1,56-5,00)$ & 3,10 & $(1,15-4,75)$ & 0,516 & $* *$ \\
\hline \multirow[t]{4}{*}{ Clark } & III & $8(33,33 \%)$ & 7 & $(33,33 \%)$ & \multirow{4}{*}{0,218} & \multirow{4}{*}{$* * *$} \\
\hline & IV & $13(54,17 \%)$ & 7 & $(33,33 \%)$ & & \\
\hline & $\mathrm{V}$ & $3(12,50 \%)$ & 7 & $(33,33 \%)$ & & \\
\hline & unknown & 3 & 5 & & & \\
\hline \multirow[t]{3}{*}{ Ulceration } & No & $17(68,00 \%)$ & 11 & $(64,71 \%)$ & \multirow{3}{*}{1,000} & \multirow{3}{*}{$* * *$} \\
\hline & Yes & $8(32,00 \%)$ & 6 & $(35,29 \%)$ & & \\
\hline & unknown & $2 y$ & 9 & & & \\
\hline \multirow[t]{3}{*}{ Regression } & No & $25(100,00 \%)$ & 14 & $(87,50 \%)$ & \multirow{3}{*}{0,146} & \multirow{3}{*}{$* * *$} \\
\hline & Yes & . & 2 & $(12,50 \%)$ & & \\
\hline & unknown & 2 & 10 & & & \\
\hline
\end{tabular}

* t Student test, ** Mann Whitney test, *** Fisher test. SSM: spreading superficial melanoma. Quantitative data value are express in mean (except Breslow express in median) Qualitative data are express in number and percentage. 


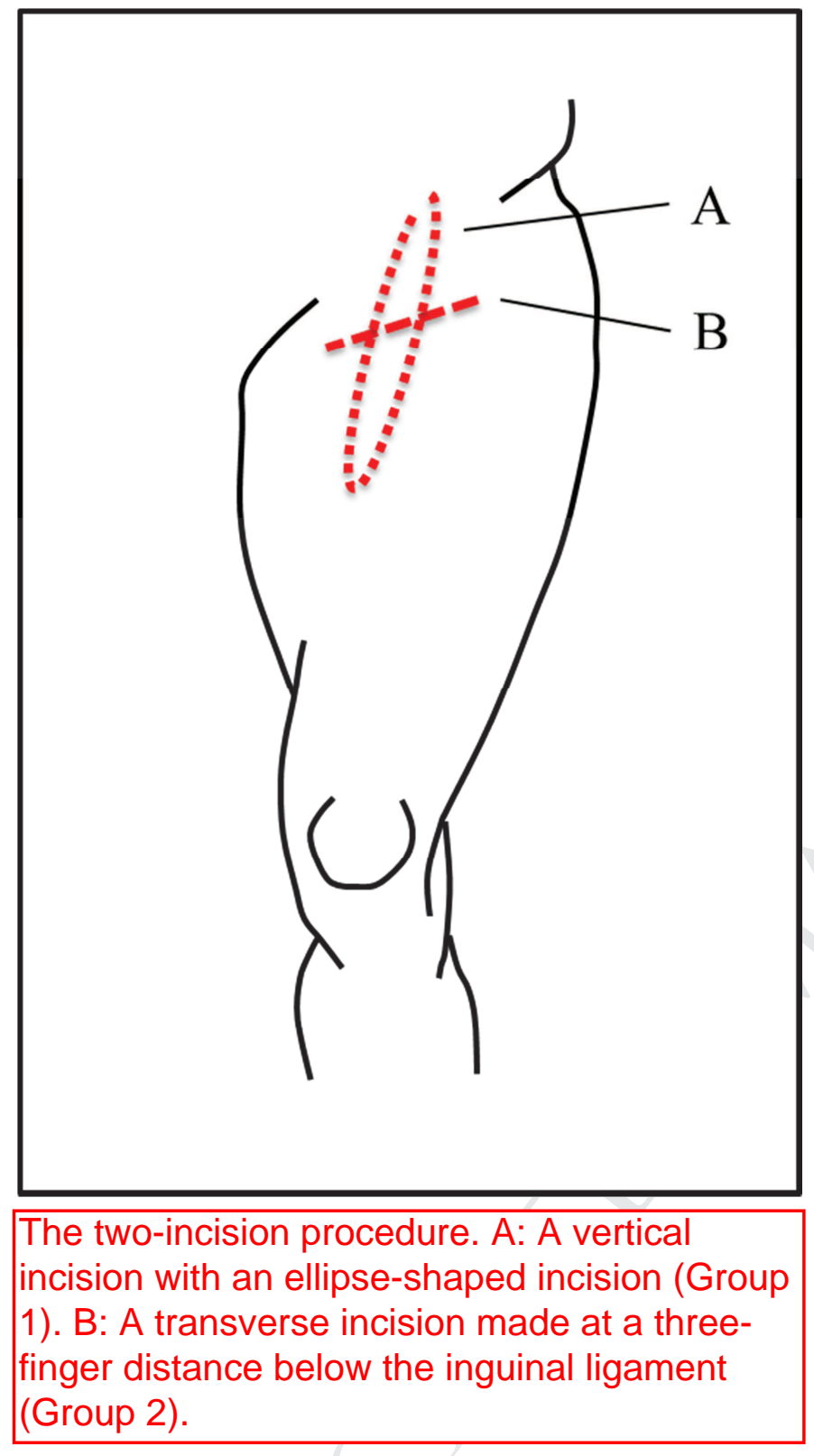



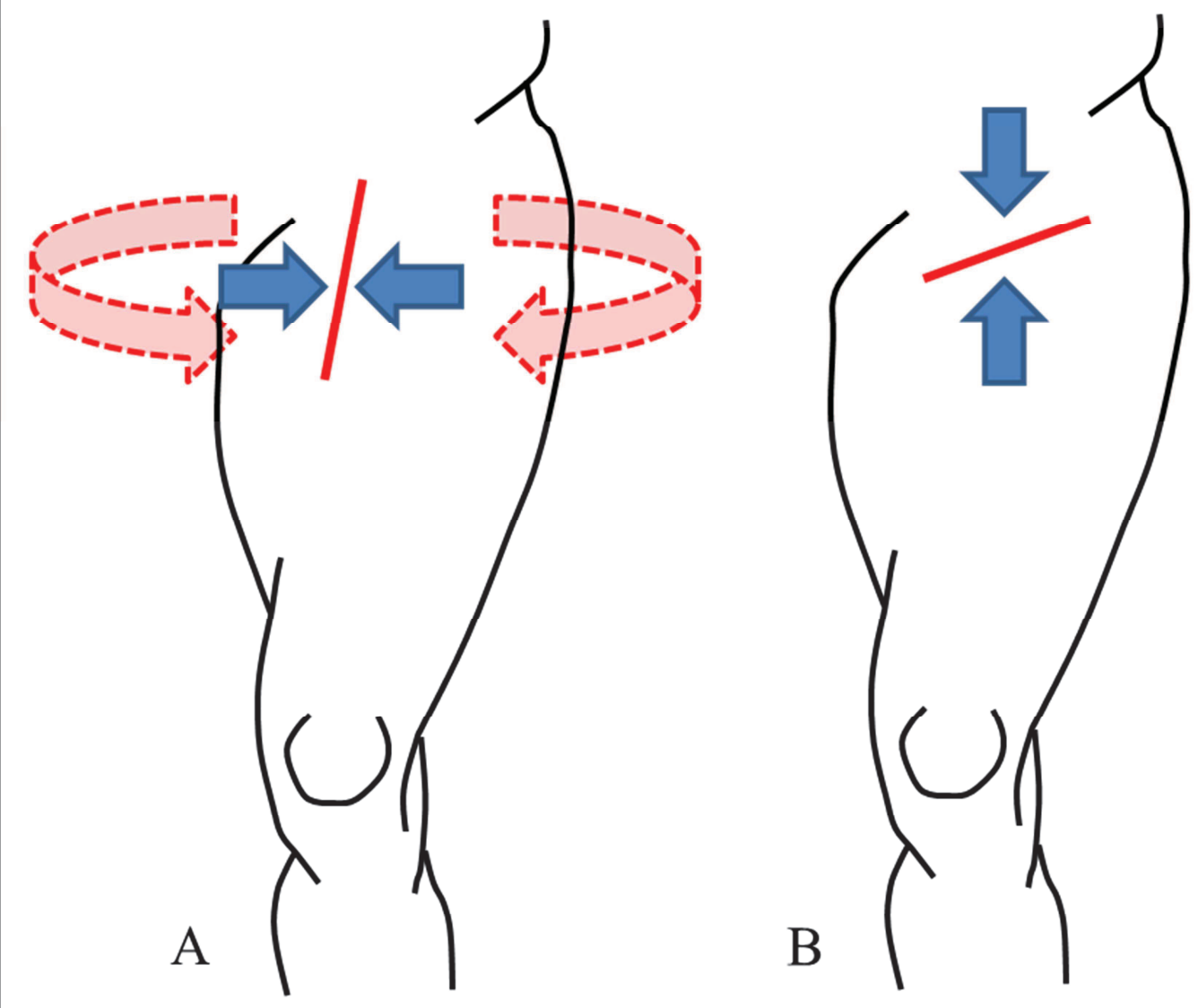

Figure 2.

A: A vertical incision. Blue arrows indicate the healing process; red arrows indicate the 'tourniquet effect'. B: A transverse incision. Blue arrows indicate the healing process that may avoid the 'tourniquet effect'. 